\title{
3. NOTAS
}

1. Dolors Comas d'Argemir, nos proporcionó los nombres y direcciones de los antropólogos portugueses, que posteriormente Raúl Iturra, acabó de completar. Si bien en esta ocasión no hemos utilizado estas informaciones, esperamos hacerlo en un futuro próximo.

2. Alta-fulla, Akal, Ayuso, Ariel, Adara (desaparecida), Anthropos, Alianza, Barral, Daimon, Dopesa (desparecida), Edicusa (Cuadernos para el Diálogo), Empúries, Edicions 62, Fondo de Cultura Económica, Fontanella, Grijalbo-Crítica, Istmo, La Piqueta, Labor, Laia, Llibres de la Frontera, Mitre, Península, Siglo XXI de España, Taurus, Tecnos y Teide.

\section{Contestaron nuestras circulares un total de 141 personas.}

4. Un artículo de Fermín del Pino (1978): “Antropólogos en el exilio" (In: El exilio español de 1939. Taurus. Madrid) presenta una buena revisión de los antropólogos en el exilio. También resulta útil la consulta de A. Palerm (1980): "Sobre los antropólogos españoles de México desde el exilio de 1939". (In:Actas I Congreso Español de Antropología vol. II, pp. 173-184), así como las ponencias de Pedro Carrasco y Santiago Genovés dentro del simposio titulado Antropologia española contemporánea: España y fuera de España, celebrado en el marco del I Congreso Español de Antropología (Barcelona, 1980). También pueden ser útiles algunos libros de homenaje (cf. Escandell Terradas (Eds.) 1984 Història $i$ Antropologia a la Memòria d'Angel Palerm. Abadia de Montserrat), o bien las notas y artículos necrológicos aparecidos en algunas revistas profesionales. Entre otros, cf. Pujadas (1980): "Breu esboç de la vida i obra 
Arxiu d'Etnografia de Catalunya, $n^{\circ} 4-5,1985-86,72-79$

ISSN: 0212-0372. EISSN: 2014-3885

http://antropologia.urv.cat/revistarxiu

de Josep Ma. Batista i Roca amb motiu de la seva mort". Quaderns de I'I.C.A., 1:100-111; Esteva (1979): "Juan Comas en el contexto de una militancia indigenista", Revista Española de Antropología Americana, IX: 25-34; Alcina Franch (1983): "In memoriam Pedro Armillas García". Ethnica, 19: 127-130; F. del Pino (1984): "En memoria de D. Pedro Armillas Garcia",(1914-1984). Alcaveras, 4:25-27).

5. Sobre este viaje de carácter más o menos iniciático y también sobre la situación de la Antropología en la España de postguerra, véase el relato de Julio Caro Baroja incluído en sus magistrales memorias (cf. Caro Baroja. 1978. Los Baroja. Memorias familiares. Taurus. Madrid.). El propio Caro ha tratado estas y otras cuestiones en una serie de entrevistas (cf. Fernández Martorell, 1982. "Entrevista a Julio Caro Baroja", Comentaris d'Antropologia Cultural, 4. 7-10; "Con Don Julio Caro Baroja. Situación actual de la Antropología". Alcaveras. 1980, 0: 16-18, que no está firmada, y cambién "Entrevista a Julio Caro Baroja", publicada en Playboy, 42: 21-30). La obra de Julio Caro Baroja ha sido analizada por D.J. Greenwood (1971): "Julio Caro Baroja: sus obras e ideas", Ethnica, 2: $79-97$ y también el volumen de homenaje -Homenaje a Julio Caro Baroja- publicado por el C.I.S. y coordinado por Antonio Carreira, Jesús Antonio Cid, Manuel Gutiérrez Esteve y Rogelio Rubio (1978). Especialmente útil resulta el trabajo de A. Carreira (1978): "Julio Caro Baroja: bibliografia" (lbid. 1978: 15-41).

6. Julian Pitt-Rivers ha descrito sus experiencias antropológicas en España al menos en dos ocasiones. La primera vez en el artículo: "A Personal Memoir" (In: Homenaje a J. Caro Baroja . 1978: 887-893) y la segunda, en la entrevista concedida a Joan Prat (1982) "Entrevista amb Julian Pitt-Rivers", (Ciència, 18: 46-53).

7. La bibliografia sobre José Miguel de Barandiarán es amplia. Ver entre otros: Caro Baroja (1963): "Barandiarán y la conciencia colectiva del Pueblo Vasco" que encabeza un volumen de homenaje titulado Homenaje a Don José Miguel de Barandiarán. Una jornada cultural en compañia del maestro, (Auñamendi. San Sebastián). Otro trabajo en esta línea es el titulado Homenaje a J.M. de Barandiarán (1971). Munibe, XXIII, fasc. 2-3. y sobre todo el libro de Luis de Barandiarán Irizar (1976) José Miguel de Barandiarán, patriarca de la cultura vasca. (Sociedad Guipuzcoana de Ediciones y Publicaciones. San Sebastián). También son interesantes algunas entrevistas a J.M. de Barandiarán, como por ejemplo la publicada por Carmelo C. Ridruejo en El País (dominical 4 de marzo de 1984). Otros trabajos más analíticos sobre la obra y la influencia de J.M. de Barandiarán, serán citados posteriormente.

8. Claudi Esteva Fabregat ha explicado con precisión (cf.Autobiografía intelectual de Claudio Esteva Fabregat (1982) Anthropos. Boletín de Información y Documentación, n. 10) la situación de la antropología española en los años 50 y 60, hasta la creación de la Escuela de Estudios Antropológicos (1965) de Madrid, así como el proceso seguido en la institucionalización posterior. El testimonio de excepción que aporta Esteva en este escrito puede ser completado con otros trabajos, como por ejemplo, Curriculum Vitae de Claudio Esteva Fabregat (1970, sin pie de imprenta), Prócoro Hernández (1982) "Entrevista amb Claudi Esteva" (Ciència, 16: 44-51) y con dos tesis de licenciatura sobre la personalidad y la obra de Claudi Esteva (cf. Pepita Segura, 1984 Claudio Esteva Fabregat. Biografía de un periodo antropológico y Luis Calvo, cuya obra no hemos podido localizar).

9. En otro trabajo que estamos preparando sobre la Historia de la Antropología en España, trataremos con mucho más detalle las cuestiones que aquí sólo hemos reseñado.

10. Sin embargo, en este caso se pueden consultar las publicaciones de José Alcina Franch sobre el americanismo y la bibliografía americanista española (cf. Alcina, 1954, 1956, 1960. 1964,1972 , etc.) 
11. Los casos por ejemplo de Lluis Mallart y de Verena Stolke que habian contestado nuestra circular.

12. Siguiendo la línea de todo el volumen que se estructura en una serie de ponencias: Arqueología (coord. J. Alcina Franch), Etnohistoria (A. Jiménez Núñez), Antropología Social y Etnología (Carmelo Lisón), Antropología Biológica (José Pons) y Antropología Aplicada (Claudio Esteva), como veremos posteriormente.

13. Se recensiona, aunque parcialmente, la obra de un conjunto de autores como por ejemplo, Caro Baroja, Cucó, Esteva, Foster, Frigolé, Gregory, Lisón, Luque, Maestre, Pitt-Rivers, etc. que, lógicamente, también nosotros hemos tenido en cuenta.

14. Véanse, en este sentido, algunos artículos generales sobre la historia de la antropología en España; A. Guichot y Sierra (1927-1984) Noticia Histérica del Folklore. Junta de Andalucia. Consejería de Cultura. Sevilla; Carmelo Lisón (1971) "Una gran encuesta de 1901-1902. Notas para la historia de la antropología social en España", en el libro Antropología Social en España, pp. 97-171; el librito de M.A.Puig Samper y A. Galera (1983) La antropología española del siglo XIX (Instituto Arnau de Vilanova. C.S.I.C. Madrid.) y el largo artículo de Josep Maria Comelles (1984) "Antropología sin colonialismo. La profesión de antropólogo y el desarrollo del Estado en la España Contemporánea" (III Congreso de Antropología. San Sebastián. En prensa.) También otros dos artículos que no conocemos de primera mano (cf. Cátedra 1978 "Notes on the History of Spanish Anthropology", en History of Anthropology Newletter, 5: 10-15 y el de Fermín del Pino (1984, inédito): "Los orígenes de la Antropología en España", conferencia pronunciada dentro del ciclo Panorama de la Antropología en España, celebrado en el marco del Museo Nacional de Etnología.

Últimamente la bibliografia sobre temas históricos se ha ampliado notablemente. Presentamos pues en diferentes apartados los trabajos que consideramos más importantes:

a) Contexto intelectual de recepción del Darwinismo y la mentalidad positiva: Diego Núñez (1975) La mentalidad positiva en España (Júcar. Madrid) y del mismo autor El darwinismo en España (1977. Castalia. Madrid). También el libro clásico de Thomas Glick (1982) Daruin en España (Península. Barcelona). Las revistas Anthropos (n. 16-17. 1982), L'Avenç (n. 48. 1982) y Ciència (n. 22. 1982) dedicaron números especiales al centenario Darwin. Además de estos trabajos generales debemos nombrar otros como por ejemplo: "El miedo al mono o la causa directa de la Cuestión Universitaria en 1875" (cf. Caro Baroja: En el centenario de la Institución Libre de Enseñanza .Tecnos. Madrid.), "El darwinismo en la Sociedad Antropológica Española" (cf. Galera, Puig-Samper, Pelayo. 1982, In: II Congreso de la Sociedad Española de las Ciencias. Jaca), "El evolucionismo en la práctica científica de los biólogos españoles" (cf. Sala Català. Asclepio, XXXIII. C.S.I.C. Madrid. pp. 81-125). El mundo de las revistas ha sido abordado por L.A. Sánchez Gómez (1985): "Antropología y revistas culturales españolas durante la Restauración (1874-1898)". In: (II Jornadas de Etnologia de Castilla- La Mancha. Ciudad Real. pp. 33-41).

b) Pensamiento de algunos autores caracterizados de la época: "El doctor González de Velasco y la Antropologia Española en el siglo XIX" (cf. M.A. Puig-Samper. 1982. Asclepio); "Julián Sanz del Río, renovador del pensamiento español del siglo XIX" (cf. T. Rodríguez de Lecea. 1980. In: Actas del 1 Congreso Español de Antropologia. Vol II. pp. 87-99), o bien "Urbano González Serrano: Piscología, sociología y antropología en el krausismo español del último tercio del siglo XIX". (cf. Antonio Jiménez Garcia. 1980. In: I Congreso Español de Antropología. Vol II. pp. 101-107.)

c) Instituciones: Sobre la Sociedad Antropológica Española fundada por el Dr. González de Velasco (cf. A. Verde Casanova. 1980. "La primera sociedad antropológica de España." 1 Congreso Español de Antropología. Vol. II. pp. 17-38); la Institución Libre de Enseñanza (cf. Cacho Viu. 1980. La Institución Libre de Enseñanza. I. Origenes y etapa universitaria. (1860-80). 
Rialp. Madrid, En el centenario de la Institución Libre de Enseñanza, de varios autores. Tecnos. Madrid. Y también el número monográfico de Historia 16 (año $\mathrm{V}, \mathrm{n}$. 49). Por lo que se refiere al tema de los museos, véanse especialmente los artículos de Pilar Romero de Tejada sobre el Museo Nacional de Etnología (cf. Romero de Tejada. 1975. "La antropología y los museos". In: Primera Reunión de Antropólogos Españoles. pp. 339-347; "La Antropología espanola y el Museo Nacional de Etnología (1875-1974)." In: Rivera (1977) Antropología de España y América. pp. 295-322; "Los viajeros españoles del siglo XIX y las colecciones del Museo Nacional de Etnología." In: Actas del l Congreso Español de Antropología. 1980. Vol. II. pp. 39-62 y, finalmente, "Situación de la etnología en los Museos españoles." In: Actas del II Congreso de Antropología. 1985. pp. 40-44). En Cataluña, han trabajado el tema Dolors Llopart y Marta Montmany (cf. Llopart. 1978. "Museus comarcals a Catalunya." Perspectiva Escolar, 29: 61-64 y Llopart y Montmany. 1981. "Entorn del projecte de Museu Català d'Arts, Indústries i Tradicions Populars" Canya, 0, 30-33.)

d) Expediciones: Véanse los artículos de Fermín del Pino (1984): "La expedición Malaspina y la Etnología". In: Exposición del Centro Cultural de la Villa. Madrid; también Pilar Romero en su articulo ya citado y Ana Verde (1980): "Notas para el estudio etnológico de las expediciones científicas españolas a América durante el siglo XVIII." en la Revista de Indias.

e) La Encuesta del Ateneo de 1901-1902: No podíamos acabar esta larga nota sin una mención explícita a la Información promovida por la Sección de Ciencias Morales y Politicas del Ateneo de Madrid, en el campo de las costumbres populares y en los tres más caracteristicos de la vida: el nacimiento, el matrimonio y la muerte, la famosa encuesta de 1901-1902. Los trabajos que conocemos sobre este tema son: Lisón (op. cit.); Limón (1977) "Avance de la edición crítica sobre la información que en el campo de las costumbres de nacimiento, matrimonio y muerte en España, realizó la Sección de Ciencias Morales y Politicas del Ateneo de Madrid (1901 - 1902)" Instituto de Etnografia y Folklore Luis Hoyos Sainz. Vol. VIII. pp. 303-403, y del mismo autor Costumbres andaluzas de nacimiento, matrimonio y muerte. 1981. Diputación Provincial de Sevilla; Manuel A. Fariña (1985) ha preparado la edición de la obra de Juan Bethencourt Alfonso titulada Costumbres populares Canarias de nacimiento, matrimonio y muerte (Publicaciones cientificas del Excm. Cabildo Insular de Tenerife) y Juan Francisco Blanco (1986) los materiales de la Encuesta recogidos en Salamanca con el título de Usos y costumbres de nacimiento, matrimonio y muerte en Salamanca (Centro de Cultura Tradicional. Diputación de Salamanca). También muy recientemente se ha reeditado la obra de Pere Ballester "Costumbres Populares de Menorca. Contestación al Cuestionario de la Sección de Ciencias Sociales y Políticas del Ateneo de Madrid."- Mahón. 1905 - en un volumen titulado Estudis d'Antropologia de Menorca (1986. Consell Interinsular de Menorca. Col-lecció Capcer). Además no debemos olvidar los trabajos de Foster (1980): "Folklore y costumbres del embarazo. Nacimiento e infancia." In: Kenny y De Miguel (Eds.) La Antropologia Médica en España; Romero de Tejada "La encuesta del Ateneo de 1901 y la cultura vasca." In: III Congreso de Antropología. (San Sebastián, en prensa); y Angels Roque "Ritos de pasaje en la Sierra de la Demanda burgalesa." In: I Congreso de Etnología y Folklore en Castilla y León (Soria, en prensa).

15. Además de los trabajos que citamos en el texto, hay otros de carácter histórico, imprescindibles para comprender la evolución de las ciencias antropológicas en Andalucía. Véanse, en este sentido; E. Aguilar (1984) "La revista mensual de Filosofía, Literatura y Ciencias de Sevilla." In: Rodríguez Becerra (Ed.) Antropologia Cultural de Andalucia, pp. 177-184; Blas Vega y Eugenio Cobo (1981) "Biobibliografía de Antonio Machado y Alvarez. Estudio Preliminar." In: El Folklore Andaluz. Ayuntamiento de Sevilla. Editorial Tres, Catorce, Diecisiete; Rodríguez Becerra (1985) "La obra folklórica de Luís Montoto. Aportaciones a la historia de la antropología cultural española." In: Actas del 11 Congreso de Antropología, pp. 106-109; José Ramón Jiménez Benitez (1984) "Estudio Preliminar" In: Noticia bistórica del Folklore, de Alejandro Guichot y Sierra (Junta de Andalucía - Consejeria de Cultura) y, del mismo autor: Alejandro Guichot y Sierra (1859-1941) (Tesis doctoral. Universidad de Sevilla). Finalmente, un libro colectivo-Homenaje a D. Antonio Machado y Alvarez- está en prensa (Ayuntamiento de Sevilla) desde hace tiempo. 
16. Véase la excelente tesis doctoral de Fernando Estévez (1985): Indigenismo, raza y evolución en el pensamiento antropológico canario en los siglos XVIII y XIX (Universidad de La Laguna) y también el libro de José Pérez Vidal (1982): Los estudios de Folklore Canario. 1880-1980. (Mancomunidad de Cabildos de Las Palmas. Ministerio de Cultura). Otros trabajos de orientación historiográfica son los de E. López Rodríguez (1983): "Biobibliografia de José Pérez Vidal." In: Separata del II Congreso Iberoaméricano de Antropologia (Las Palmas); Manuel Farina (1981): "La aportación del Dr. D. Juan Bethencourt Alfonso a los estudios arqueológicos y antropológicos en Canarias." In: I Congreso Iberoamericano de Estudiosos del Folklore, y, del mismo autor: "El Dr. Juan Bethencourt Alfonso o el compromiso con Canarias." Gaceta de Canarias, II (5): 26-39 (1981), y aún la "Introducción" al libro de J. Bethencourt (1985) Costumbres populares canarias de nacimiento, matrimonio y muerte. Act. Museo Etnográfico. Aula de Cultura de Tenerife. También es úcil la consulta de los trabajos de L. Diego Cuscoy (1975): "Notas para una historia de la Antropologia Canaria." In: Millares Torres (Ed.) Historia General de las Islas Canarias (Las Palmas), o bien "El museo canario, factores determinantes de su continuidad." en El Museo Canario, 42: 7-8 (1982).

17. Jesús Azcona ha dedicado al menos estos 6 artículos sobre el tema (cf. Azcona, 1981 "Notas para una historia de la antropología vasca: Telesforo de Aranzadi y José Miguel de Barandiarán." Ethnica, 17: 63-84; "La delimitación antropológica y etnológica de lo vasco y de los vascos." Cuadernos de Etnología y Etnografia de Navarra, 40: 753-802 (1982); "La escuela histórica de Viena y la antropología vasca. Su alcance epistemológico en el contexto de la antropología europea." Cuadernos de Etnología y Etnografía de Navarra, 43: 137-151 (1984); "Sobre algunas dimensiones histórico-sociales de lo vasco en el pensamiento antropológico y etnológico." Langaiak, 8-9: 103-110 (1985) y "Problemas y perspectivas de la antropología en el País Vasco" (1986, inédito). Algunos de estos artículos han sido reelaborados en el libro del propio autor titulado Etnia y nacionalismo vasco. Una aproximación desde la antropologia. Anthropos. Barcelona. 1984).

Además de esta larga lista, debemos citar los trabajos de Joxemartin Apalategi (1981): "Introducción a la historia crítica de la producción oral popular vasca." Ethnica, 17-18: y Apalategi (1984): "Pour une histoire critique et comparée de l'anthropologie basque: ou en sommes-nous aujour d'hui?" In: Eusko-Ikaskuntza. Sociedad de Estudios Vascos. San Sebastián. Pueden ser útiles, para acabar de complementar, las referencias sobre José Miguel de Barandiarán citadas en la nota 7 y algunos trabajos, de los que tenemos referencia pero que no conocemos de primera mano, como por ejemplo: A. Manterola (1984) Euskaldunak. La etnia vasca. Ayerbe. San Sebastián; Caro Baroja (1979) Balance de cuarenta y dos años. Zarauz y A. Goikoetxea (1985) Telesforo de Aranzadi. Vida y Obra. Sociedad de Ciencias Aranzadi. San Sebastián.

18. Los trabajos historiográficos sobre el folklore y la etnografía en Catalunya son, también, relativamente numerosos. El primer escrito es del folklorisca Joan Amades (cf. Ibid. 1974. "El folklore a Catalunya." Miscellanea Barcinonensia, XXXVIII. Ajuntament de Barcelona.), el cual también trabajó en una extensa bibliografia sobre folklore que ha quedado inédita. Trabajos posteriores son los de Joan Prat (Ibid. 1980. "Els estudis etnogràfics i etnològics a Catalunya." Quaderns de 1'I.C.A., 1: 30-63; 1985. "El folklore catalán ¿ideología o ciencia?." In: Actas del Il Congreso de Antropologia. pp 110-120 y 1981. "El folklore i l'etnologia a la premsa catalana no diària." Canya, 0:7-15); Llorenç Prats (Ibid. 1981. L'estudi de la cultura popular a Catalunya: els folkloristes. Tesis de licenciatura. Universitat de Barcelona; "Els precedents dels estudis etnològics a Catalunya: folklore i etnografia (1853-1959). Ciència, 11: 20-27. 1982; "Sobre el caràcter conservador de la cultura popular." In: Llopart, Prat, Prats (Eds.) La cultura popular a debat. Alta-fulla. Serveis de Cultura Popular). Este mismo autor está finalizando su tesis doctoral - L'origen de l'interès per la cultura popular a Catalunya. La Renaixença. - dedicada al tema. Prats, Llopart y Prat (1982) escribieron un libro de síntesis titulado La cultura popular a Catalunya. Estudiosos $i$ Institucions (1853-1981). Serveis de Cultura Popular. Barcelona. Algunos autores han trabajado sobre figuras concretas: J.J. 
Pujadas. 1980 "Breu esboç de la vida i l'obra de Josep M. Batista i Roca amb motiu de la seva mort." Quaderns de l'I.C.A., 1: 100-111; Carbó, Pla, Prats tienen inédita una Bibliografia de Joan Amades y Llorenç Prats (1980) "La transición del folklore a la etnografia en Cataluña. La obra de R. Violant i Simorra." Ethnica, 16: 104-120.

Otras investigaciones que debemos citar son: "Els centres relacionats amb la cultura popular a Catalunya." presentada por el Seminari de Cultura Popular del I.C.A. en el Col-loqui sobre l'estudi de la cultura popular (Saifores, 1981) y diferentes prólogos de Josefina Roma a reediciones de libros clásicos (cf. Miscelànea Folklorica. 1981: Arxiu de Tradicions Populars. 1980, etc.) asi como algunos trabajos de Dolors Comas d'Argemir sobre el folklore y la escuela (cf. Ibid. 1982 "Laplicació del folklore a l'activitat escolar. Una reflexió a la seva significació." Perspectiva Escolar, 69: 24-27, y dentro del mismo volumen "Aplicació del folklore a l'activitat escolar. Una aproximació bibliogràfica.").

19. La bibliografía de carácter histórico que conocemos sobre las Castillas es limitada, ya que, además de lo mencionado en la larga nota 14, se reduce a unos pocos títulos sobre Luís de Hoyos Sainz (cf. Hoyos Sancho. 1969. "Nuestros antecesores: Telesforo de Aranzadi y Luís de Hoyos Sainz". Actas del I Congreso Nacional de Artes y Costumbres populares pp. 59-65; Caro Baroja. 1976. "Don Luís de Hoyos Sainz. 1868-1951". Publicaciones del Instituto de Etnografía y Folklore.Diputación Provincial de Santander. Vol. III. pp. 7-18; Sanemeterio, M. 1976. "Don Luis de Hoyos Sainz y la Antropología Española." Publicaciones del Instituto de Etnografia y Folklore. Diputación Provincial de Santander. pp. 10-30; Carmen Ortiz. 1985. "La obra antropológica de Don Luís de Hoyos Sainz." In: Etnologia. II Jornadas de Etnología de CastillaLa Mancha. pp. 17-32.)

20. Los 11 artículos llevan el mismo título: Etnología y folklore en.... Manuel Mandianes se ocupa de Galicia; Angel Aguirre del País Vasco i Navarra; Luís V. Elías de la Rioja; Josefina Roma de Cataluña; Julián San Valero del País Valenciano y Murcia; Sebastián Trías de Mallorca; Luís Calvo de Castilla; Salvador Rodríguez de Andalucía; Javier Marcos de Extremadura e Isabel Badillo de Canarias.

21. El mismo equipo que hemos trabajado en la confección de Treinta Años de Literatura Antropológica sobre España, estamos preparando una ponencia para el IV Congreso de Antropología que se celebrará en Alicante en la que desarrollaremos ampliamente este tema.

22. Conocemos el programa de otro Coloquio -Fêtes et Liturgie (1985) - realizado en la Casa de Velázquez, pero no la publicación.

23. Con anterioridad, la unidad departamental de Antropología de la Universidad de La Laguna, dirigida por Alberto Galván, había organizado anualmente, y desde 1977, la celebración de unas Semanas de Antropologia Canaria que no fueron publicadas.

24. El Centro de Cultura Tradicional de la Exma Diputación de Salamanca; el Centro de Estudios del Folklore del Exm. Ayuntamiento de Zamora; el Centro Etnográfico de Documentación de la Exma. Diputación d Valladolid; el Grupo Castellano de Etnología y Antropología de León; el Laboratorio de Antropología Cultural de la Universidad de León y también la Sección de Etnografia del Departamento de Arqueología y Prehistoria de la Faculcad de Filosofia y Letras de la Universidad de Salamanca.

25. De todas formas, parece que la celebración de Semanas Culturales en las que la etnografía y la etnología ocupan un papel importante es notable en todo el País Vasco (cf. Del Valle. 1981. "Visión General de la Antropología Vasca." Ethnica, 18: 142 y ss.).

26. Zaragoza, Córdoba y Palma de Mallorca. En el artículo ya cicado de Angel Gari (1984) "Antropología Social y Cultural." (In: V Jornadas sobre el estado actual de los estudios sobre 
A ragón. pp. 67-107) el autor detalla otros numerosos congresos y jornadas, de carácter más local, pero que a menudo han generado publicaciones. Debemos señalar también la celebración de las Jornadas de Estudios Folklóricos Aragoneses, los años 1965, 1966, 1968 y 1969.

27. También unas Jornadas de Etnografía organizadas por la Consejería de Educación, Cultura y Deportes y el Museo Etnográfico de la Rioja, los primeros días de junio de 1986, en Logroño.

28. Tradición y Cultura (organizado por el Centro de Cultura Tradicional de la Diputación de Salamanca y la Junta de Castilla y León, en Salamanca. Julio de 1986); IV Jornadas de Etnologia de Castilla-La Mancha (Albacete. Septiembre de 1986); Cultura Tradicional y Popular en Castilla y León. (II Ciclo de seminarios. Valladolid. Marzo de 1986); Semana de Etnologia en Burgos (Burgos. Octubre de 1986); Antropoloxia, Etnoloxia y Llingua. (V Xornaes d'Estudiu. Oviedo. Octubre de 1986).

29. La Primera Reunión de Antropólogos Españoles (Sevilla, 1973) constó, como ya hemos indicado, de las siguientes ponencias: Arqueologia (Alcina Franch), Etnohistoria (Jiménez Núñez), Antropología Social y Etnología (Lisón Tolosana), Antropología Biológica (Pons Rosell), Antropología aplicada (Esteva Fabregat) y Acuerdos y Resoluciones (Ballesteros Gaibrois). El presidente fue A. Jiménez Núñez, director del Departamento de Antropología y Etnología de América de la Universidad de Sevilla y en el volumen de actas se publicaron los acuerdos y resoluciones tomadas por los 87 asistentes al Congreso.

La Segunda Reunión de Antropólogos Españoles (Segovia, 1974) fue presidida por Manuel Ballesteros y los 200 asistentes se dividieron en cinco grandes ponencias: Antropología biológica $(J$. Pons y A. Valls), Arqueología (L. Pericot), Etnohistoria y Lingüística (A. Jiménez), Etnología y Antropología Social (J. Alcina e I. Moreno) y un simposio: Emigración en España (C. Esteva). Los prólogos a los dos libros de actas fueron escritos por Miguel Rivera ( que iniciaba una polémica en defensa de la concepción holística de la antropología cultural).

El I Congreso Español de Antropología (Barcelona, 1977) fue presidido por Claudi Esteva que pronunció una larga "Alocución presidencial". Los simposios fueron los siguientes: Etnohistoria, Sociedades campesinas en España, Relaciones interdisciplinarias (Ecología), Antropología Biológica, Historia de la antropología, Antropología española contemporánea (España y fuera de España) y Arqueologia Americana.

El Il Congreso de Antropología (Madrid, 1981), organizado por la Asociación Madrileña de Antropologia, concedió la presidencia honoraria a Julio Caro Baroja, y la introducción del volumen de actas corrió a cargo de Rafael Llavona, secretario del Congreso. Los simposios se estructuraron en torno de los siguientes títulos: Situación actual de la antropología, Teoría y método antropológicos (Sesión de metodologia, historia de la antropología, Homenaje a Angel Palerm, Teoria y relaciones interdisciplinarias), Etnicidad, Naciones, regiones y pueblos, Temas libres (mesa redonda sobre comunidades pesqueras), Programa de técnicas audiovisuales, Metodología, Realizaciones.

El III Congreso de Antropologia (Donostia, 1984) fue inagurado por José Miguel de Barandiarán y constó de los simposios siguientes: Etnicidad y nacionalismo (Problemas teóricos, Estudios de casos, Metodología y técnicas), Antropología simbólica (Simbolismo y Salud), Métodos y técnicas, Antropología de la mujer, Antropología de la pesca, Arte y antropologia, Antropología vasca, Estado actual de la antropología, Estado profesional de la antropología en el Estado Español, Cine etnográfico y Temas Libres (Aspectos teóricos, monografias).

\section{Comunicación personal de Julian Pitt-Rivers.}

31. Véanse, también, las ediciones preparadas por Spencer (1970), Bailey (1971 y 1973), Boissevain y Friedl (1975), Safa y Du Toit (1975), Reiter (1975), Smith (1977), Dorson (1979), Soliday (1980), Foster y Brandes (1980), Ortner y Whitead (1981), Harloe (1981), Wilk y Arnould (1984), Sheper-Hugues (e.p.), etc. 
32. Otros seminarios y ciclos de conferencias no han sido editados. Ejemplos en este sentido serian El trabajo de campo en Antropología (Asociación Madrileña de Antropología, 1982); Panorama de la Antropologia en España (A.M.A., 1984-1985); Antropología de la Fiesta (Instituto de Estudios Turolenses. Teruel, 1984); Antropologia de les societats pageses (Trobades Científiques de la Mediterrània. Maó. 1985); Mito. ritual y religiosidad popular (Universidad Autónoma de Madrid. 1985); Las señas de identidad de pueblos y comarcas (Cursos Internacionales de Benidorm. Alicante, 1986); Antropoloxia e Madernidade (Santiago de Compostela, 1986), etc.

\section{Comunicación personal de Angel Aguirre.}

\section{Comunicación personal de Honorio Velasco, Angeles Díaz y Fermín del Pino.}

35. Véanse: Severino Pallaruelo (1984) Las navatas. El transporte de troncos por los ríos del Alto Aragón. y M. Cabezón, A. Castelló y T. Ramón (1984) La alfarería en Huesca. Descripción y localización.

36. Por lo que se refiere a las revistas extranjeras, habiamos preparado, con la ayuda de los utilisimos catálogos internacionales -Ulrich's International Periodicals Directory. A Bowker Serials Bibliography (1983) y Irregular Serials and Annuals. An International Directory (1984)- un listado de revistas para vaciar. No obstante, problemas técnicos de última hora nos lo impidieron.

37. Además de estas revistas, se debería hablar de las revistas profesionaies pertenecientes al ámbito de la Sociología. Estas están perfectamente representadas en la publicación de J. Díez Nicolás, J. de Pino Artacho y R. Gobernado Arribas (1984) Cincuenta años de Sociología en España (Universidad de Málaga. Caja de Ahorros de Antequera) y a este trabajo remitimos al lector interesado.

38. Véase un útil catálogo de autores de la Revista de Estudios Extremeños (años 1927-1971) publicado en dos volúmenes monográficos, y también un cuidado estudio de J. Marcos Arévalo (1986): "Etnografia y Folklore en Extremadura" In: Aguirre (Ed.) La Antropologia Cultural en España, pp. 351-360.

39. Véase la parte final de la publicación donde presentamos los indices.

40. Y esto por la sencilla razón que no conocemos de primera mano la totalidad del corpus recensionado y juzgar y catalogar exclusivamente a partir de los títulos y libros - que no siempre reflejan con fidelidad el contenido real de los artículos - n : pareció excesivamente peligroso. En un futuro próximo hemos previsto la confección de este indice temático, que confeccionaremos tan pronto como podamos ofrecer las garantias de éxito que, en estos momentos, aún no tenemos.

41. Cada tres o cada cinco años, según nuestras posibilidades técnicas y económicas. 